Correspondence: Cleante Scarduelli, Director of Intensive Cardiopulmonary Rehabilitation Unit, ASST Mantova, Via Galilei 7, 46100 Mantua, Italy.

Tel. +39.345.2254959.

E-mail: cleante@libero.it

Contributions: CS, conception, acquisition and interpretation of data, drafting of the work; FI, acquisition, analysis and interpretation of data, revising the work; $\mathrm{MB}$, conception, interpretation of data, revising the work; FS, conception, interpretation of data, revising the work; $\mathrm{MG}, \mathrm{AP}, \mathrm{GC}$, acquisition and interpretation of data, revising the work; GG, conception, acquisition of data, revision of the work; SS, conception, analysis of the data; GL, statistical analysis; GDD, interpretation of data, revision of the final version; $\mathrm{CB}$, design of the work, interpretation of data, revision of the final version of the work. All the authors have read and approved the final version of the manuscript and agreed to be accountable for all aspects of the work.

Funding: This research did not receive any specific grant for funding agencies from the public, commercial, or not-for-profit sectors.

Conflict of interest: The authors declare that they have no competing interests, and all authors confirm accuracy.

Ethics approval: This study was approved by the Valpadana ATS (Cremona, Italy) Ethics Committee on 7 July 2020 (Study code 952020-OSS_FARM-MN30).

Institutional approval: This study was approved by the ASST Mantova on 20 August 2020 (deliberation $\mathrm{N}^{\circ}$ 1043).

Consent to participate: Not applicable.

Patient consent for publication: Not applicable.

Availability of data and material: Data are available from the corresponding author on reasonable request.

Acknowledgments: This study would not have been possible without the work and dedication of all of the health care workers on the frontline fighting COVID-19. This report is dedicated to all patients and health care workers who died due to COVID-19 in Italy and around the world. We would also like to thank: Vanni Galavotti and Fabrizio Squeri who provided and cared for study patients; Editage (www.editage.com) for English language editing.

Key words: Pulmonary embolism; venous thromboembolism; COVID19; enoxaparin; respiratory failure.

Highlights:

- Despite intermediate-to full-dose enoxaparin, $12 \%$ of our patients developed PEs

- Among our patients who underwent CTPA, $50 \%$ had confirmed PEs

- We hypothesize that our low PE prevalence may be due to enoxaparin treatment

Received for publication: 2 January 2021.

Accepted for publication: 4 March 2021.

${ }^{\circ}$ Copyright: the Author(s), 2021

Licensee PAGEPress, Italy

Monaldi Archives for Chest Disease 2021; 91:1758

doi: 10.4081/monaldi.2021.1758

This article is distributed under the terms of the Creative Commons Attribution Noncommercial License (by-nc 4.0) which permits any noncommercial use, distribution, and reproduction in any medium, provided the original author(s) and source are credited.

\section{Pulmonary embolism in patients with severe COVID-19 treated with intermediate- to full- dose enoxaparin: A retrospective study}

\author{
Cleante Scarduelli ${ }^{1}$, Francesco Inglese ${ }^{2}$, \\ Massimiliano Beccaria ${ }^{2}$, Fabio Spreafico ${ }^{2}$, \\ Martina Garuti ${ }^{2}$, Antonietta Pecoriello ${ }^{2}$, Giulia \\ Cervi $^{2}$, Graziana Greco² ${ }^{2}$, Sara Scarduelli ${ }^{3}$, \\ Giuseppe Lucchini ${ }^{4}$, \\ Giuseppe De Donno ${ }^{2}$, Claudio Borghi ${ }^{3}$
}

${ }^{1}$ Intensive Cardiopulmonary Rehabilitation Unit, ASST Mantua; ${ }^{2}$ Pulmonology and Respiratory Intensive Care Unit, ASST Mantua; ${ }^{3}$ Internal Medicine Department of Medical and Surgical Sciences, University of Bologna; ${ }^{4}$ Bio-statistical Service, ASST Mantua, Italy

\begin{abstract}
Coronavirus disease (COVID-19) may predispose patients to pulmonary embolism (PE), despite standard thromboprophylaxis. Our retrospective study aimed to report the prevalence of PE in patients with COVID-19 and severe respiratory failure (SRF) treated with intermediate- to full-dose enoxaparin. We analyzed data from patients with COVID-19 pneumonia and SRF admitted to our Respiratory Intensive Care Unit (RICU) from February 27 to April 20, 2020. All patients received at least intermediate-dose enoxaparin (40 mg twice daily). Computed tomography pulmonary angiography (CTPA) was used to detect PE. Ninety-two patients with COVID-19 pneumonia and SRF were admitted to our RICU. Twenty-two patients underwent CTPA (24\%), 11 of whom had PEs $(12 \%)$. We hypothesize that the enoxaparin treatment may be responsible for the lower prevalence of PE as compared to previous reports of similar patients, even if our report had several limitations, mainly the small sample size.
\end{abstract}

\section{Introduction}

In December 2019, a novel coronavirus, now known as severe acute respiratory syndrome coronavirus 2 (SARS-CoV-2), quickly began to spread across Wuhan, China. It then triggered a global pandemic [1-4]. In February 2020, cases of coronavirus disease (COVID-19) began appearing abruptly in the Lombardy region of northwest Italy and quickly overwhelmed its healthcare system. By December 18, 2020, there are 1,921,778 patients diagnosed with COVID-19 in Italy with 67,8944 deaths [5].

Most patients with COVID-19 present with mild symptoms such as fever, cough, chills, muscle pain, and a loss of taste or smell. However, a significant proportion (10-29\%) of hospitalized patients develop severe respiratory failure (SRF) and acute respiratory distress syndrome (ARDS) requiring admission to the intensive care unit (ICU) $[1,2,5]$. Venous thromboembolism 
(VTE) is now recognized as one of the predominant cardiovascular hazards in patients with COVID-19 [6-11]. Recent studies report that patients with severe COVID-19 also often have coagulopathies with a predisposition for arterial and venous thromboembolisms, and therefore may benefit from anticoagulant therapy [610]. Recent studies have demonstrated a high prevalence of VTE in patients with COVID-19 admitted to ICU, particularly lower leg deep vein thromboses (DVTs) in $25 \%$ of 81 patients and pulmonary embolisms (PEs) in $20.6 \%$ of 107 patients [9-13]. The frequency of symptomatic VTE in patients in ICU with COVID-19 has been reported to be $27 \%$ [11].

Our study reports a case series of 92 patients with COVID-19 and SRF who were admitted to our respiratory intensive care unit (RICU) and who were treated with intermediate- or full-dose enoxaparin. The purpose of our study was to evaluate the prevalence of PE in patients with COVID-19 and SRF treated with intermediate- to full-dose enoxaparin.

\section{Methods}

Ninety-two patients diagnosed with COVID-19 and SRF [mean arterial oxygen partial pressure/fractional inspired oxygen $\left.\left(\mathrm{PaO}_{2} / \mathrm{FiO}_{2}\right)<300 \mathrm{~mm} \mathrm{Hg}\right]$ were admitted to our RICU for noninvasive positive-pressure ventilation (NIV) from February 27 to April 20, 2020.

Our RICU is a 15-bed ward with non-invasive cardiopulmonary monitoring and a non-invasive mechanical ventilator designated to each bed. This unit provides 600 minutes of nursing care per bed. It is staffed by three pulmonologists from 8 AM to 8 PM, one pulmonologist from 8 PM to 8 AM on workdays, and one pulmonologist on public holidays.

All patients were diagnosed with COVID-19 based on the World Health Organization guidelines [14]. Emerging data suggested an increased prevalence of VTE among critically ill patients with COVID-19 [6,10,12], despite having undergone standard thromboprophylaxis. Therefore, we treated these patients with intermediate- to full-dose enoxaparin. Patients were generally treated with intermediate- dose enoxaparin (40 mg twice daily). However, if their D-dimer levels were higher than $3000 \mathrm{ng} / \mathrm{mL}$ and/or if they experienced an acute worsening of their respiratory or hemodynamic status, they were treated with full-dose enoxaparin $(1 \mathrm{mg} / \mathrm{kg}$ of body weight twice daily). Patients with renal failure were treated with adjusted doses of enoxaparin based on their anti-Xa activity. After PEs were diagnosed, patients were treated with full-dose enoxaparin.

Patients with D-dimer levels $>3000 \mathrm{ng} / \mathrm{mL}$ and/or acute worsening of their respiratory or hemodynamic status underwent computed tomography pulmonary angiography (CTPA) to confirm or exclude PE. If a patient's clinical status did not allow for a safe transfer to the radiology department (e.g., they were dependent on NIV), the patient was treated with full-dose enoxaparin. The choice to use intermediate- or full-dose enoxaparin was always made in consideration of the patient's risk for bleeding [15]. The clinical characteristics, adverse events probably related to enoxaparin therapy [thrombocytopenia (i.e., platelet level $<50,000 / \mu \mathrm{L}$ ), hematomas, bleeding requiring transfusion of two or more units of concentrated red blood cells], and outcomes of these consecutive patients with COVID-19 were retrospectively analyzed. This study was approved by the Valpadana ATS ethics committee (Cremona, Italy) on July 7, 2020. The study code is 95-2020-OSS_FARMMN30).
Informed consent was waived due to the emergency situation regarding COVID-19 at the time.

\section{Statistical analysis}

The association between categorical variables was evaluated using Pearson's chi-square test. Statistical comparisons for continuous variables were conducted using the unpaired Student's $t$-test. All tests were two-tailed, and p-values of $<0.05$ were considered statistically significant. The analysis was conducted using the Statistical Package for Social Sciences, version 23 (Armonk, New York, NY, USA).

\section{Results}

Ninety-two patients with diagnosed COVID-19 were admitted to our RICU between February 27 and April 20, 2020. Twenty-two (24\%) patients underwent CTPA-PEs were confirmed in $11(12 \%)$ of these patients. Table 1 shows the characteristics and clinical course of all the included patients.

The mean age of the patients was $58 \pm 11$ years (range $28-85$ years); and $21(22.8 \%)$ patients were female. Obesity was significantly prevalent ( $45 \%$ of patients), and the most common comorbidities were hypertension (46\%) and diabetes mellitus (19\%).

The patients had SRF (mean $\mathrm{PaO}_{2} / \mathrm{FiO}_{2}$ of $143 \pm 45 \mathrm{~mm} \mathrm{Hg}$ ) and high D-dimer levels (the mean D- dimer level was $2698 \pm 2673$ $\mathrm{ng} / \mathrm{mL}$ ). The mean $\mathrm{PaO}_{2} / \mathrm{FiO}_{2}$ was $122 \pm 47 \mathrm{~mm} \mathrm{Hg}$ in patients who died and $146 \pm 44 \mathrm{~mm} \mathrm{Hg}$ in patients who survived $(\mathrm{p}=0.10)$.

Ten (11\%) patients developed adverse events [three patients had intramuscular hematomas, two had thrombocytopenia (i.e., platelet level $<50,000 / \mu \mathrm{L}$ ), and five had bleeding requiring the transfusion of two or more units of concentrated red blood cells], eight of whom were treated with full-dose and two with intermediate-dose enoxaparin. None of these 10 patients died. Enoxaparin was discontinued in four patients and was temporarily reduced in six patients.

Eleven (12\%) patients died in hospital. The mean age of the deceased patients was statistically different from that of the surviving patients $(70 \pm 9$ years $v s 56 \pm 11$ years, respectively; $\mathrm{p}<0.0001)$. No statistically significant difference in hospital mortality was found between patients with and without PE $(p=0.90)$. Table 2 shows the characteristics of patients with COVID-19 with and without PE.

The mean $\mathrm{PaO}_{2} / \mathrm{FiO}_{2}$ was $133 \pm 47 \mathrm{~mm} \mathrm{Hg}$ in patients with $\mathrm{PE}$ and $144 \pm 45 \mathrm{~mm} \mathrm{Hg}$ in patients without $\mathrm{PE}(\mathrm{p}=0.46)$. The mean Ddimer level was $4582 \pm 4424 \mathrm{ng} / \mathrm{mL}$ in patients with $\mathrm{PE}$ and $2634 \pm 2529 \mathrm{ng} / \mathrm{mL}$ in patients without $\mathrm{PE}(\mathrm{p}=0.20)$. Moreover, the body mass index (BMI) was greater than $30 \mathrm{~kg} / \mathrm{m}^{2}$ in five $(45 \%)$ patients with $\mathrm{PE}$ and in 40 (49\%) patients without PE.

\section{Discussion}

Pulmonary embolism was diagnosed in $11(12 \%)$ patients admitted to our RICU for COVID-19 pneumonia and SRF, despite treatment with intermediate- to full-dose enoxaparin. However, the frequency of $\mathrm{PE}$ in our patient population was lower than that previously reported in similar patients [12]. Although our study prob- 
ably underestimated the real frequency of PE, because only a small portion (24\%) of patients underwent CTPA, it is possible to assume that the reduced PE incidence may have been due to the use of a higher-than-prophylactic dose of enoxaparin.

The frequency of VTE is highest in the ICU setting and has ranged from $25 \%$, when symptomatic disease is considered, to $69 \%$, when surveillance venous ultrasonography is performed [6,9,10-13].

Our patients underwent CTPA only if there was a clinical suspicion of $\mathrm{PE}$ and/or in the presence of elevated D-dimer levels, and if a patient's clinical status allowed for a safe transfer to the radiology department. Considering these assumptions, 50\% of our patients who underwent CTPA had confirmed PEs.

Pneumonia in patients with COVID-19 can lead to sepsis and

Table 1. Characteristics of 92 patients with COVID-19 upon admission to the respiratory intensive care unit and during their hospital course.

\begin{tabular}{|c|c|}
\hline Characteristic & Results \\
\hline Age (y) & $58(11)$ \\
\hline Female patients & $21(22 \%)$ \\
\hline BMI $>30 \mathrm{~kg} / \mathrm{m}^{2}$ & $42(45 \%)$ \\
\hline Hypertension & $43(46 \%)$ \\
\hline Diabetes & $18(19 \%)$ \\
\hline $\mathrm{PaO}_{2} / \mathrm{FiO}_{2}(\mathrm{~mm} \mathrm{Hg})$ & $143(45)$ \\
\hline $200 \mathrm{~mm} \mathrm{Hg}<\mathrm{PaO}_{2} / \mathrm{FiO}_{2} \leq 300 \mathrm{~mm} \mathrm{Hg}$ & $11(12 \%)$ \\
\hline $100 \mathrm{~mm} \mathrm{Hg}<\mathrm{PaO}_{2} / \mathrm{FiO}_{2} \leq 200 \mathrm{~mm} \mathrm{Hg}$ & $67(73 \%)$ \\
\hline $\mathrm{PaO}_{2} / \mathrm{FiO}_{2}<100 \mathrm{~mm} \mathrm{Hg}$ & $14(15 \%)$ \\
\hline D-dimer level (ng/mL) & $2698(2673)$ \\
\hline D-dimer level $\leq 1000 \mathrm{ng} / \mathrm{mL}$ & $26(28 \%)$ \\
\hline $1000 \mathrm{ng} / \mathrm{mL}<$ D-dimer level $\leq 3000 \mathrm{ng} / \mathrm{mL}$ & $34(37 \%)$ \\
\hline D-dimer level >3000 ng/mL & $32(35 \%)$ \\
\hline Lactate dehydrogenase level (U/L) & $765(323)$ \\
\hline Fibrinogen level (mg/dL) & $636(168)$ \\
\hline Patients who underwent CTPA & $22(24 \%)$ \\
\hline Pulmonary embolism diagnosed via CTPA & $11(12 \%)$ \\
\hline Enoxaparin-related adverse effects & $10(11 \%)$ \\
\hline Patients who died in hospital & $11(12 \%)$ \\
\hline Mean age of patients who died (y) & $70(9)^{*}$ \\
\hline Mean age of patients who survived (y) & $56(11)^{*}$ \\
\hline
\end{tabular}

the release of inflammatory cytokines, including interleukin (IL)6, IL-8, and tumor necrosis factor-a [16]. Inflammatory cytokines can promote blood coagulation in various manners [10]. The reported incidence of disseminated intravascular coagulation (DIC) in patients who have died from COVID-19 pneumonia is $74 \%$ [6]. A high prevalence of in situ micro-thrombosis, suspected to be due to endothelial injury from direct viral infection, has also been described [17-19]. Inflammation, DIC, hypoxemia, obesity, and immobility may predispose patients with COVID-19 and SRF to the development of thromboembolic complications $[1-4,12,20]$.

Emerging data suggest an increase in the prevalence of VTE among patients with COVID-19, especially among patients with more severe disease $[10,12]$.

To our knowledge, this study is the first to analyze data from patients with COVID-19 admitted to the RICU for non-invasive mechanical ventilation. Due to the small number of patients with PEs, we did not identify any statistically significant differences in hospital mortality, D-dimer levels, or $\mathrm{PaO}_{2} / \mathrm{FiO}_{2}$ between patients with and without PE. However, we identified a trend toward a higher D-dimer level and lower $\mathrm{PaO}_{2} / \mathrm{FiO}_{2}$ in patients with $\mathrm{PEs}$. An elevated D-dimer level is a sign of excessive activation of coagulation and hyperfibrinolysis. Thus, D-dimer levels are often used to detect the presence of an active thrombus. The D-dimer level has high sensitivity but low specificity [10].

The D-dimer cut-off value of $3000 \mathrm{ng} / \mathrm{mL}$ has a sensitivity, specificity, and negative predictive value for PE of $76.9 \%, 94.9 \%$, and $92.5 \%$, respectively [10].

Patients admitted to our RICU had SRF with moderate to severe ARDS [21]. It has recently been reported that the presence of ARDS has the strongest association with adverse outcomes, including major arterial or venous thromboembolism, symptomatic VTE, and death [11]. Moreover, $72 \%$ of our patients had elevated D-dimer levels (i.e., $>1000 \mathrm{ng} / \mathrm{mL}$ ) and approximately onethird of patients had very elevated D-dimer levels (i.e., $>3000$ $\mathrm{ng} / \mathrm{mL})$. The prevalence of obesity $(49 \%)$ among our patients may have contributed to the increased frequency of PE, which has also been reported by other authors [12,21]. The aforementioned characteristics of our patients indicated that they had a very high thromboembolic risk. As suggested by some authors and scientific societies, we used a higher-than- prophylactic dose of enoxaparin $[10,12,20,22,23]$.

Our report had several limitations. First, this was a retrospective, single-center study with a small sample size. Second, our study probably underestimated the actual frequency of PE because only a small portion (24\%) of patients underwent CTPA, which is the gold standard for PE diagnosis [24]. Third, it was impossible to exclude the presence of $\mathrm{PE}$ at the time of admission and, thus, before starting treatment with enoxaparin.

Table 2. Characteristics of patients with COVID-19 with and without pulmonary embolism.

\begin{tabular}{lccc} 
Characteristic & Patients with PE & Patients without PE & P-value* $^{*}$ \\
Age (y) & $58(13)$ & $58(11)$ & 0.92 \\
$\mathrm{BMI}>30 \mathrm{~kg} / \mathrm{m}^{2}$ & $5(45 \%)$ & $40(49 \%)$ & 0.52 \\
\hline $\mathrm{PaO}_{2} / \mathrm{FiO}_{2}$ & $133(47)$ & $144(45)$ & 0.46 \\
$\mathrm{D}-$ dimer level $(\mathrm{ng} / \mathrm{mL})$ & $4582(4424)$ & $2634(2529)$ & 0.20 \\
\hline $\mathrm{LDH}$ level (U/L) & $900(412)$ & $745(308)$ & 0.15 \\
Ferritin level (ng/mL) & $1687(1432)$ & $2102(2289)$ & 0.56 \\
\hline Hospital mortality & $1(9 \%)$ & $10(12 \%)$ & 0.90 \\
\hline
\end{tabular}

The data are presented as numbers (\%) or as means (standard deviation); PE, pulmonary embolism, BMI, body mass index; LDH lactate dehydrogenase; *p-value $<0.05$ is statistically significant. 
In conclusion, to the best of our knowledge, this study is the first to report the incidence of PE among patients with severe COVID-19 who were treated with intermediate- to full-dose enoxaparin. Pulmonary embolism was diagnosed in $12 \%$ of our patients, despite the treatment dose. However, the optimal thromboprophylactic regimen in this patient population remains unknown [20,23,25]. Well- designed, randomized-controlled trials are needed to analyze the risk-benefit ratio of more aggressive lowmolecular-weight thromboprophylaxis in these patients [20,23]. A number of randomized controlled trials have been developed to evaluate the risks and benefits of anticoagulation treatment in patients with COVID-19 (visit ClinicalTrials.gov for the current list of trials) [25]. The results of these trials should shed light on the current doubts regarding this important clinical issue.

\section{References}

1. Guan WJ, Ni ZY, Yu H, et al. Clinical characteristics of coronavirus disease 2019 in China. N Eng J Med 2020;382:1708-20.

2. Huang C, Wang Y, Li X, et al. Clinical features of patients infected with 2019 novel coronavirus in Wuhan, China. Lancet 2020;395:497-506

3. Chen N, Zhou M, Dong X, et al. Epidemiological and clinical characteristics of 99 cases of 2019 novel coronavirus pneumonia in Wuhan, China: a descriptive study. Lancet 2020;395: 507-13.

4. Wang D, Hu B, Hu C, et al. Clinical characteristics of 138 hospitalized patients with 2019 novel coronavirus-infected pneumonia in Wuhan, China. JAMA 2020;323:1061-9.

5. Ministero della Salute. [Covid-19, i casi in Italia il 18 dicembre: situazione Italia al 18 Dicembre].[in Italian]. Accessed: 18 December 2020. Available from: http://www.salute.gov.it/portale/nuovocoronavirus/dettaglioNotizieNuovoCoronavirus.jsp $? 1$ ingua $=$ italiano $\&$ menu $=$ notizie $\& p=$ dalministero $\& i d=4539$

6. Tang N, Li D, Wang X, Sun Z. Abnormal coagulation parameters are associated with poor prognosis in patients with novel coronavirus pneumonia. J Thromb Haemost 2020;18:844-7.

7. Tang N, Bai H, Chen X, Gong J, Li D, Sun Z. Anticoagulant treatment is associated with decreased mortality in severe coronavirus disease 2019 patients with coagulopathy. J Thromb Haemost 2020;18:1094-9.

8. Zhang Y, Xiao M, Zhang S, et al. Coagulopathy and antiphospholipid antibodies in patients with Covid-19. N Eng J Med 2020;382:e38.

9. Klok FA, Kruip MJ, Van der Meer NJ, et al. Incidence of thrombotic complications in critically ill ICU patients with COVID-19. Thromb Res 2020;191:145-7.

10. Cui S, Chen S, Li X, Liu S, Wang F. Prevalence of venous thromboembolism in patients with severe novel coronavirus pneumonia. J Thromb Haemost 2020;18:1421-4.

11. Piazza G, Campia U, Hurwitz S, et al. Registry of arterial and venous thromboembolic complications in patients with COVID-19. J Am Coll Cardiol 2020;76:2060-72.
12. Poissy J, Goutay J, Caplan M, et al; Lille ICU Haemostasis COVID-19 Group. Pulmonary embolism in COVID-19 patients: awareness of an increased prevalence. Circulation 2020;142:184-6.

13. Lodigiani C, Iapichino G, Carenzo L, et al. Venous and arterial thromboembolic complications in COVID-19 patients admitted to an academic hospital in Milan, Italy. Thromb Res 2020;191:9-14.

14. World Health Organization. Laboratory testing for 2019 novel coronavirus (2019-nCoV) in suspected human cases: interim guidance. Accessed: 10 August 2020. Available from: https://www.who.int/publications/i/item/10665-331501

15. Kresoja KP, Ebner M, Rogge NI, et al. Prediction and prognostic importance of in-hospital major bleeding in a real-world cohort of patients with pulmonary embolism. Int J Cardiol 2019;290:144-9.

16. Qin C, Zhou L, Hu Z, et al. Dysregulation of immune response in patients with COVID-19 in Wuhan, China. Clin Infect Dis 2020;71:762-8.

17. Ackermann M, Verleden SE, Kuehnel M, et al. Pulmonary vascular endothelialitis, thrombosis, and angiogenesis in COVID19. N Eng J Med 2020;383:120-8.

18. Varga Z, Flammer AJ, Steiger P, et al. Endothelial cell infection and endothelitis in COVID- 19. Lancet 2020;395:417-8.

19. Wichmann D, Sperhake JP, Lutgehetmann M, et al. Autopsy findings and venous thromboembolism in patients with COVID-19 (2020). Ann Intern Med 2020;173:268-77.

20. Bikdeli B, Madhavan MV, Jimenez D, et al. COVID-19 and thrombotic and thromboembolic disease: implications for prevention, antithrombotic therapy, and follow-up: JACC Stateof- the-art review. J Am Coll Cardiol 2020;75:2950-73.

21. Ranieri VM, Rubenfeld GD, Thompson BT, et al. Acute respiratory distress syndrome: the Berlin Definition. JAMA 2012;307:2526-33.

22. Simonnet A, Chetboun M, Poissy J, et al. High prevalence of obesity in severe acute respiratory syndrome coronavirus-2 (SARS-CoV-2) requiring invasive mechanical ventilation. Obesity (Silver Spring) 2020;28:1195-9.

23. British Thoracic Society. BTS Guidance on venous thromboembolic disease in patients with COVID-19. Accessed 10 August 2020. Available from: https://brit-thoracic.org.uk/ document-library/quality-improvement/covid-19/bts-guidance-on-venous-thromboembolic-disease-in-patients-withcovid-19

24. Konstantinides SV, Meyer G, Becattini C, et al. 2019 ESC guidelines for the diagnosis and management of acute pulmonary embolism developed in collaboration with the European Respiratory Society (ERS). Eur Heart J 2020;41:543-603.

25. National Institutes of Health. Coronavirus disease 2019 (COVID-19) treatment guidelines. Accessed December 12, 2020. Available from: https://www.covid19treatmentguidelines.nih.gov/ 